\title{
Use of vortex flows for aerodynamic threshing of agricultural crops
}

\author{
Vladimir Safonov ${ }^{1}$, Eduard Zhalnin ${ }^{2}$, Marina Lapa ${ }^{1, *}$, and Dmitry Bordan ${ }^{1}$ \\ ${ }^{1}$ Federal State Autonomous Educational Institution of Higher Education "Sevastopol State \\ University", Sevastopol, Russian Federation \\ ${ }^{2}$ Federal Research Agro-Engineering Center VIM, 1st Institutskiy proezd, 5, Moscow, 109428, Russia
}

\begin{abstract}
The presence of self-oscillations in the vortex tube allowed threshing of various agricultural crops in it, such as rice, corn, wheat, oats, etc. For aerodynamic threshing of agricultural crops, the following installations were used: for threshing of selection samples, a tube $50 \mathrm{~mm}$ in diameter; for threshing corn cobs with a pipe with a diameter of $300 \mathrm{~mm}$, $500 \mathrm{~mm}$ and a diameter of $1000 \mathrm{~mm}$; threshing unit (pipes with a diameter of $1.2 \div 2 \mathrm{~m}$ ), an unconventional vortex aerodynamic stand for threshing crops. According to the results of experiments, the threshing parameters are presented.
\end{abstract}

\section{Introduction}

The works $[1,2]$ are devoted to the issues of threshing of agricultural crops. The existing mechanical threshing methods carry out significant microtrauma and crushing of the grain upon contact with mechanical moving parts. This can be excluded if the aerodynamic threshing method in a vortex flow is used.

The purpose of scientific research is an investigation of parameters of aerodynamic threshing of agricultural crops.

\section{Methods and materials}

The equations of motion in cylindrical coordinates in the form of Navier-Stokes take the form of [3, p.29]: the radial component - formula (1), the tangential component - formula (2), the axial component - formula (3).

$$
\begin{gathered}
\rho\left(\frac{\partial V_{r}}{\partial t}+V_{r} \frac{\partial V_{r}}{\partial r}+\frac{V_{\theta}}{r} \frac{\partial V_{r}}{\partial \theta}-\frac{V_{\theta}^{2}}{r}+V_{z} \frac{\partial V_{r}}{\partial z}\right) \\
=-\frac{\partial p}{\partial r}+\mu\left\{\frac{\partial}{\partial r}\left[\frac{1}{r} \frac{\partial}{\partial r}\left(r V_{r}\right)\right]+\frac{1}{r^{2}} \frac{\partial^{2} V_{r}}{\partial \theta^{2}}-\frac{2}{r^{2}} \frac{\partial V_{\theta}}{\partial \theta}+\frac{\partial^{2} V_{r}}{\partial z^{2}}\right\}+\rho f_{r},
\end{gathered}
$$

\footnotetext{
* Corresponding author: siver_info@mail.ru
} 
where $\rho$ is the air density $\left(\mathrm{kg} / \mathrm{m}^{3}\right), \mu$ is the air viscosity $(\mathrm{Pa} \cdot \mathrm{s}), V_{r}$ is a radial velocity component $(\mathrm{m} / \mathrm{s}), V_{\theta}$ is a tangential air velocity component $(\mathrm{m} / \mathrm{s}), r$ is a vortex radius $(\mathrm{m})$,

$V_{z}$ is an axial component of the air velocity $(\mathrm{m} / \mathrm{s}), f_{r}$ is a component of the force in the radial direction $(\mathrm{N}), z$ is a direction of the axis along the vortex, $\theta$ is an angle of velocity deviation in the direction tangential to the vortex (degrees), $t$ is the time (s).

$$
\begin{gathered}
\rho\left(\frac{\partial V_{\theta}}{\partial t}+V_{r} \frac{\partial V_{\theta}}{\partial r}+\frac{V_{\theta}}{r} \frac{\partial V_{\theta}}{\partial \theta}-\frac{V_{r} V_{\theta}}{r}+V_{z} \frac{\partial V_{\theta}}{\partial z}\right) \\
=-\frac{1}{r} \frac{\partial p}{\partial \theta}+\mu\left\{\frac{\partial}{\partial r}\left[\frac{1}{r} \frac{\partial}{\partial r}\left(r V_{\theta}\right)\right]+\frac{1}{r^{2}} \frac{\partial^{2} V_{\theta}}{\partial \theta^{2}}-\frac{2}{r^{2}} \frac{\partial V_{r}}{\partial \theta}+\frac{\partial^{2} V_{\theta}}{\partial z^{2}}\right\}+\rho f_{\theta},
\end{gathered}
$$

where $f_{\theta}$ is a component of the force in the direction of the velocity $V_{\theta},(\mathrm{N})$,

$$
\begin{gathered}
\rho\left(\frac{\partial V_{z}}{\partial t}+V_{r} \frac{\partial V_{z}}{\partial r}+\frac{V_{\theta}}{r} \frac{\partial V_{z}}{\partial \theta}-\frac{V_{r} V_{\theta}}{r}+V_{z} \frac{\partial V_{z}}{\partial z}\right) \\
=-\frac{\partial p}{\partial z}+\mu\left\{\frac{1}{r} \frac{\partial}{\partial r}\left[r \frac{\partial V_{z}}{\partial r}\right]+\frac{1}{r} \frac{\partial^{2} V_{z}}{\partial \theta^{2}}+\frac{\partial^{2} V_{z}}{\partial z^{2}}\right\}+\rho f_{z},
\end{gathered}
$$

where $f_{z}$ is a component of the force in the direction of the $\mathrm{z}$ axis $(\mathrm{N})$.

We assume that the viscosity $\mu$ is equal to zero, the gas is ideal in general, the entropy change $d S=0$, the motion is established behind the nozzle section and the state is fixed, and the angular velocity profile $\omega=$ const fills a significant part of the vortex tube section. If in the radial direction, due to density fluctuations (or for some other reason), a small velocity fluctuation $V_{r}$ occurred, then the elementary volume shifted along the radius at a distance $\delta r$. We consider that the motion of the element is adiabatic. The equation of motion for the radial component is the equation of free oscillations around the local equilibrium position $\left(\delta_{r}=0\right)$ takes the form (4).

$$
\begin{gathered}
\frac{\partial^{2} \psi}{\partial t^{2}}=-\Omega^{2} \psi \\
\text { где } \Omega^{2}=\alpha\left(\frac{V_{\theta 0}^{2}}{r}+g\right)\left[\frac{\partial T}{\partial x}-\frac{\alpha T}{c_{p}}\left(\frac{V_{\theta 0}^{2}}{r}+g\right)\right]
\end{gathered}
$$

has meaning of the restoring force per displacement unit and mass unit,

$$
\alpha=-\frac{1}{V}\left(\frac{\partial V}{\partial T}\right)_{p}-\text { expansion coefficient at constant pressure, } \psi=\delta r .
$$

The experiment in a tube with a diameter of $50 \mathrm{~mm}$ to visualize oscillatory structures (with a bundle of rice stalks) showed that a bunch of rice stalks acquire a sinusoidal shape as a result of oscillations.

The presence of self-oscillations in the vortex tube made it possible to thresh various agricultural crops in it, such as rice, corn, wheat, oats, and others. In Fig. 1, 2, 3, 4, 6 installations for aerodynamic threshing of agricultural crops are presented. 


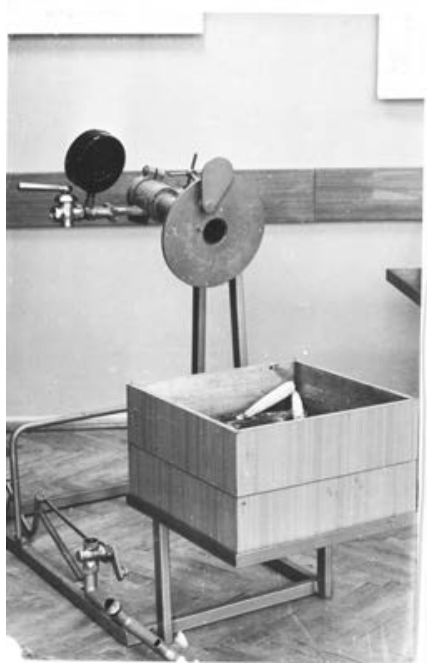

Fig. 1. Installation for threshing of selection samples, a tube with a diameter of $50 \mathrm{~mm}$.

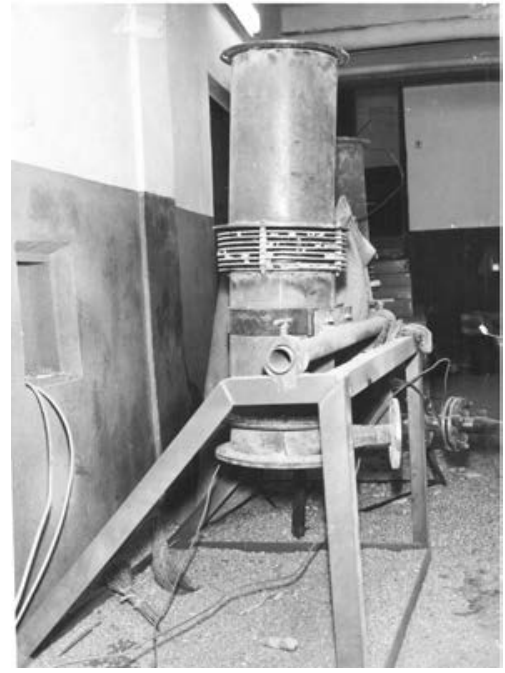

Fig. 2. Installation for threshing of corn cobs, a tube with a diameter of $300 \mathrm{~mm}$.

The casing of the installation grain collector (Fig. 2, Fig. 3) is removed and the grain falls directly on the floor, while the rods remain inside the body frame of the vortex tube.

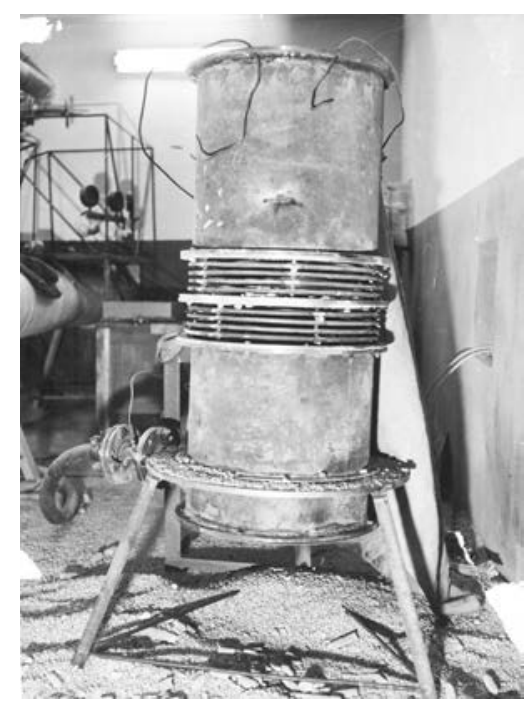

Fig. 3. Installation for threshing, a tube with a diameter of $500 \mathrm{~mm}$.

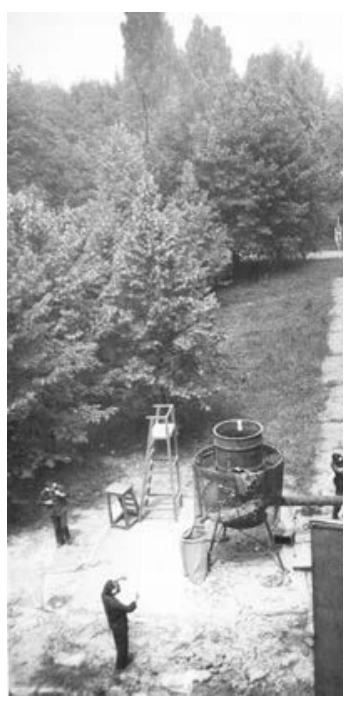

Fig. 4. The first test of an open vortex tube with a diameter of $1000 \mathrm{~mm}$ for threshing of corn cobs.

It is possible to obtain compressed air from the compressor fan installed on the ground, interfaced with the rotor of the wind turbine, as shown in Fig. 5 using a vertical shaft. 


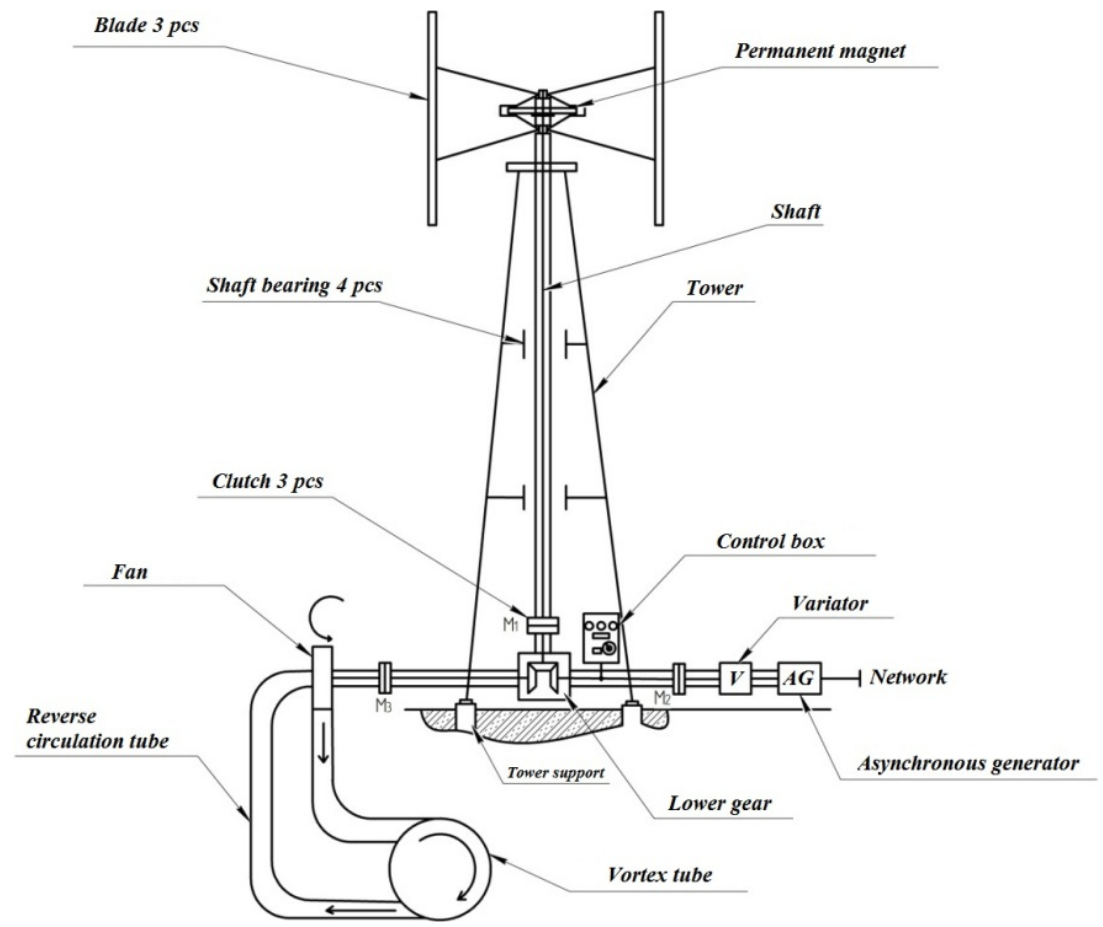

Fig. 5. Scheme of the vertical axis wind turbine with the installation for threshing.

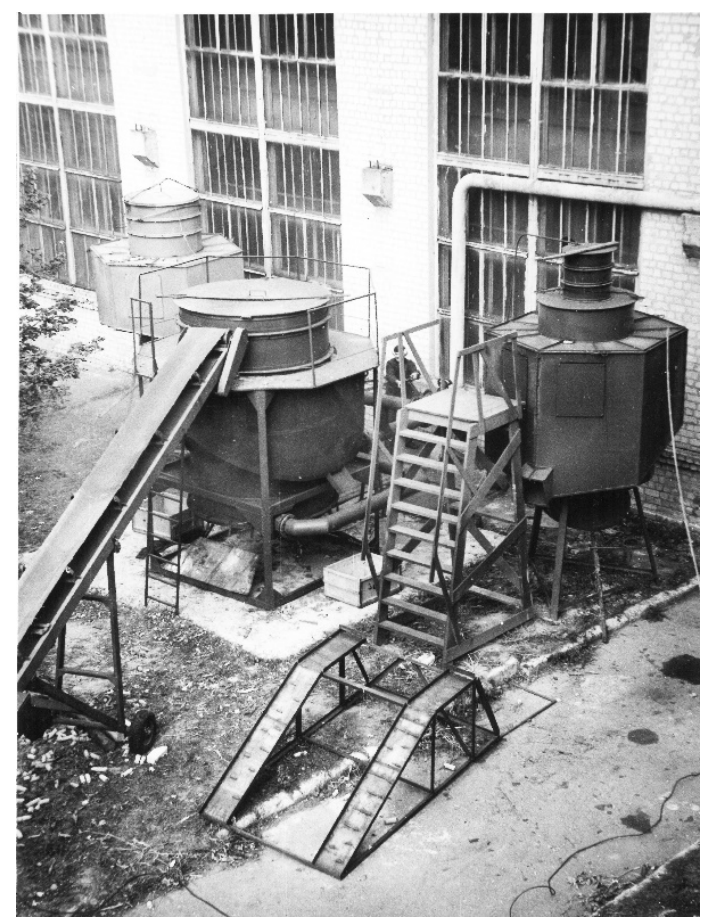

Fig. 6. Block of installations for threshing at Kharkov Aviation Institute, tubes with a diameter of $1.2 \div 2 \mathrm{~m}$. 
It seems very promising to use cob drying followed by threshing in a vortex tube, which can significantly reduce the cost of cob drying that constitute a significant amount compared to threshing, if the drying is accompanied with the inclusion of increased air pressure to turn the cob mass, and if after the end of the drying, threshing is performed by increasing the air pressure. For these purposes, it is possible to use vortex tubes with a diameter significantly larger than $2 \mathrm{~m}-15 \div 18 \mathrm{~m}$. This method will significantly reduce energy costs and threshing time and is fundamentally new in the technology of drying and threshing. Fig. 7 shows an unconventional vortex aerodynamic stand of threshing of agricultural crops, manufactured by the Sevastopol machinery and repair plant for the Institute of VIM (Moscow City) according to the inventions of Safonov V. A.

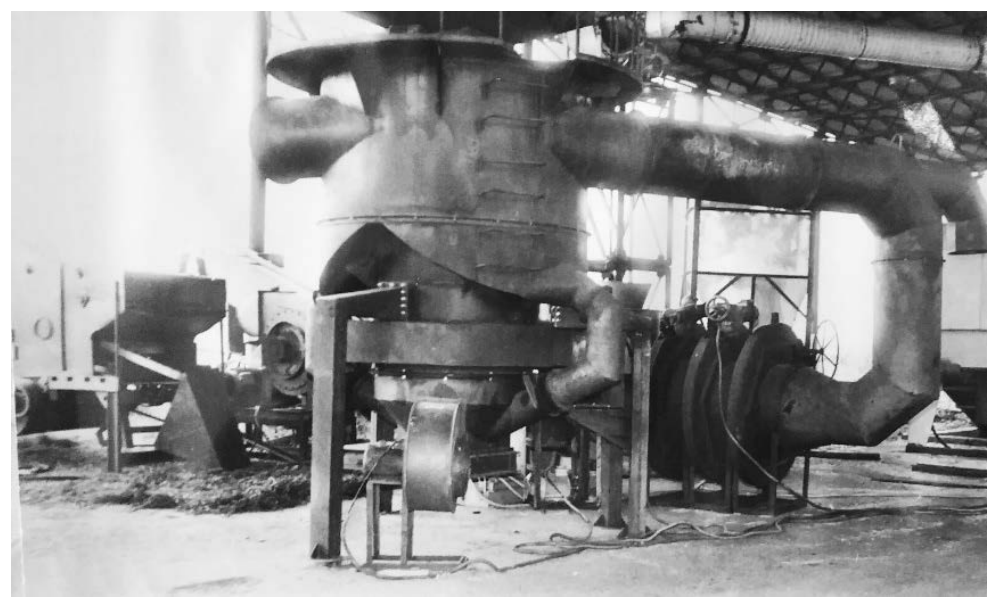

Fig. 7. Unconventional vortex aerodynamic stand of threshing of agricultural crops.

The experimental stand contains a vortex tube with a diameter of $1.2 \mathrm{~m}$ with a grain collector casing around it. Fig. 7 shows the auxiliary fan below. Adjusting orifice diaphragms are installed on the return air duct to change the air flow rate and air pressure at the entrance into the vortex tube. The bottom fan can dry the threshed mass. Designed for development of various constructions and threshing modes of various cultures.

Moreover, experiments on threshing of seeds of various vegetable crops were conducted.

\section{Results and discussion}

Corn cobs and sunflower caps were threshed in installations. Exceptional threshing of all grain residues was observed. For corn, end pieces were threshed first, then the middle part of the cob. This makes it possible for the selection to choose the most productive middle part of the grains on the cob after stopping the air supply, and to turn on the air supply again after removing the unproductive end grains.

Threshing time in a tube with a diameter of $1,2 \mathrm{~m}$ depends on the humidity of the cobs and does not exceed 5 minutes with a cob mass of $150 \mathrm{~kg}$. In a tube with a diameter of 50 $\mathrm{mm}$ in a nozzle section with a cone angle of a hot flow tube of 3 degrees, threshing of $1 \mathrm{cob}$ is performed in 3-5 seconds at a pressure of $0.2 \times 10^{5} \mathrm{~Pa}$. In the same tube, threshing of various headed grains was carried out at a pressure of $0.01 \mathrm{~Pa}$, that is, in a fan mode. Table 1 presents the minimum air pressure and its consumption per $1 \mathrm{~kg}$ of grain for threshing of various crops. 
Table 1. Parameters for threshing of various crops

\begin{tabular}{|l|l|c|c|}
\hline № & \multicolumn{1}{|c|}{ Threshed crops } & $\begin{array}{r}\text { Minimum air } \\
\text { pressure kg/cm }\end{array}$ & $\begin{array}{c}\text { Air consumption }\left(\mathrm{m}^{3}\right) \\
\text { per } 1 \mathrm{~kg} \text { of grain }\end{array}$ \\
\hline 1 & Oats & $0,03 \div 0,05$ & $\approx 10$ \\
\hline 2 & Rice & $0,04 \div 0,05$ & $\approx 10$ \\
\hline 3 & Flax & $0,05 \div 0,06$ & $\approx 10$ \\
\hline 4 & Millet & $0,05 \div 0,06$ & $\approx 10$ \\
\hline 5 & Sorghum & 0,07 & $\approx 10$ \\
\hline 6 & Triticale (a hybrid of wheat and rye) & 0,1 & $\approx 10$ \\
\hline 7 & Wet wheat ears & 0,2 & $\approx 12$ \\
\hline 8 & Corn & $1,5 \div 2$ & $\approx 2 \div 1,5$ \\
\hline
\end{tabular}

A characteristic feature of the use of a vortex tube for threshing is a sharp decrease in the required pressure with an increase of the vortex tube diameter. When threshing corn cobs, the pressure decreases from $2 \times 10^{5}$ Pascal (with a diameter of $50 \mathrm{~mm}$ ) to $0.07 \times 10^{5}$ Pascal with a diameter of $1.2 \mathrm{~m}$, that is, more than 30 times. Respectively, energy consumption per $1 \mathrm{~kg}$ of cob weight is reduced almost 40 times. In a vortex tube with a diameter of $50 \mathrm{~mm}$, one cob was threshed, in a tube with a diameter of $1.2 \mathrm{~m}-250 \mathrm{~kg}$, and in a tube with a diameter of $2 \mathrm{~m}-1500 \mathrm{~kg}$. Moreover, experiments on threshing of seeds of various vegetable crops were conducted.

Figure 8, 9 shows the graphs: of the specific work A for threshing of $1 \mathrm{~kg}$ of cobs (Fig. $8 \mathrm{a}$ ), of the dependence of the minimum pressure for threshing on the tube diameter (Fig. 8b), of productivity (Fig. 8c), of specific air flow (Fig. 8d), of the threshing cost of 1 ton of cobs (Fig. 9a), of power and productivity (Fig. 9b), depending on the diameter of the vortex tube.

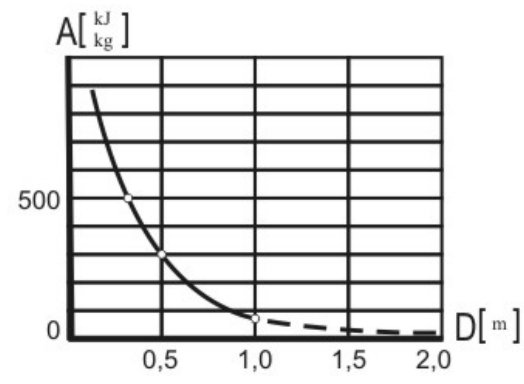

a)

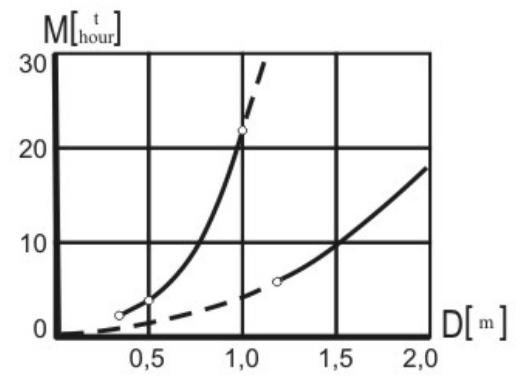

c)

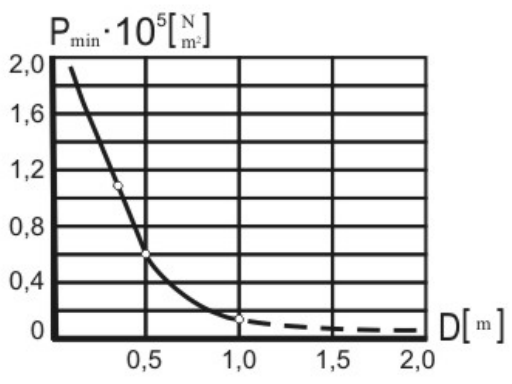

b)

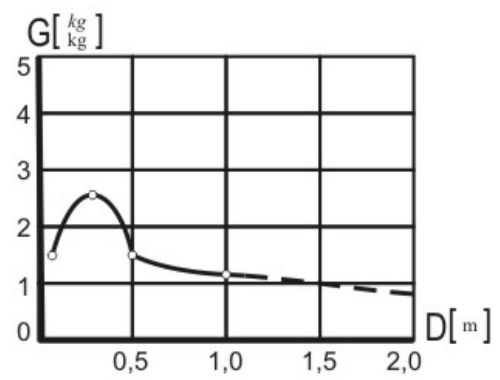

d)

Fig. 8. Characteristics of the vortex tube for threshing. 


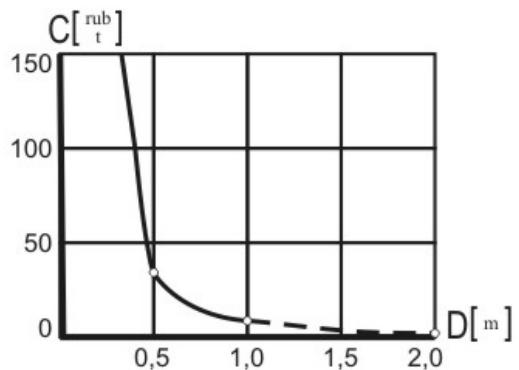

a)

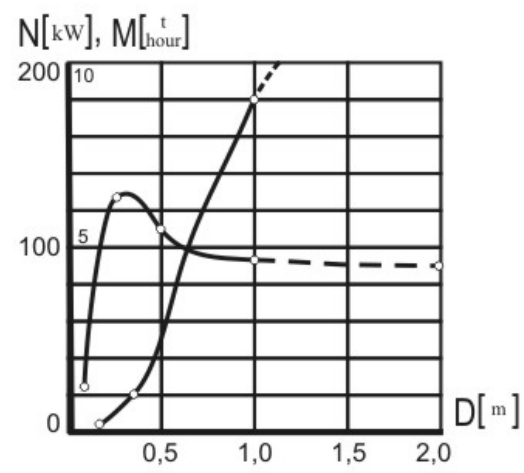

b)

Fig. 9. Threshing cost, power and productivity.

Fig. 10a presents the economic effect of use depending on the diameter of the vortex tube, fig. $10 \mathrm{~b}$ shows the dependence of the reduced costs on the diameter of the vortex tube.

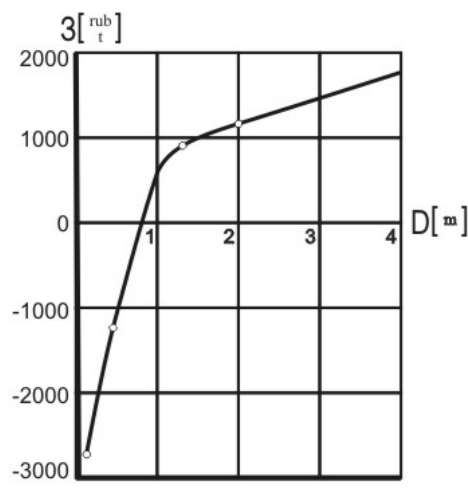

a)

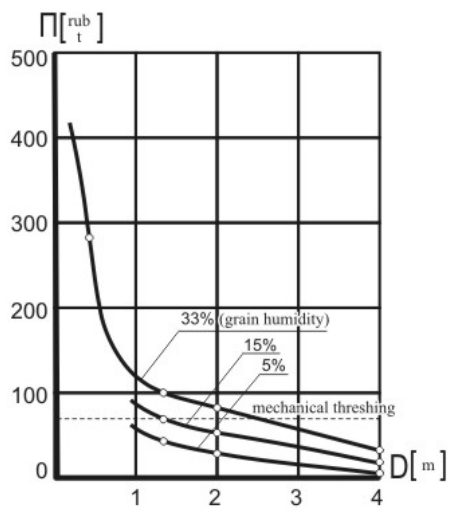

b)

Fig. 10. Economic effect and reduced costs.

The economic efficiency of the vortex installation for threshing exceeds the efficiency of threshing by the mechanical method with the vortex tube diameter more than $0.8 \mathrm{~m}$. With a smaller diameter, its efficiency is lower, however, its value lies in the undamageability of the grain, which is important for seed purposes and more complete threshing.

\section{Conclusions}

Aerodynamic threshing of various agricultural crops is possible, including those that are hard to thresh. When threshing seeds, the efficiency of such a threshing method is incommensurably higher due to the reduction of microtrauma and improved germinative capacity of an expensive seed material in the entire investigated range of diameters of the vortex tube. For such seeds as lupine, crushing is reduced from $30 \%$ to $0.5-1 \%$. When threshing corn cobs, the energy consumption for threshing becomes less than with mechanical threshing with a diameter of a vortex tube more than $0.8 \mathrm{~m}$. Simultaneous threshing and drying of grain in one device should be considered the most promising method. The application of this method will improve the drying of seeds. 


\section{References}

1. V.A. Safonov, Aerodynamic Threshing in a Vortex Tube, Collected volume of scientific papers of VIM "Intensification of grain harvesting processes", v. 113, pp. $96-98$ (1987)

2. E.V. Zhalnin, Threshing of Grain Trops: from Theory to Practice, Farm machinery operator, v. 3, pp. 62-68, (2012)

3. V. A. Safonov, Special Issues of Renewable Energy: monograph (Publishing House of the Federal State Funded Research Institution of Science, 2017) 